\title{
PCOS and Hyperprolactinemia: Conflicting Conditions or Comorbidities?
}

\author{
Alina V. Atalyan*, PhD; Eldar M. Sharifulin, PhD Student; Lyudmila M. Lazareva, PhD; \\ Yana G. Nadelyaeva, PhD; Larisa V. Suturina, PhD, ScD \\ Scientific Centre for Family Health and Human Reproduction Problems \\ Irkutsk, the Russian Federation
}

\begin{abstract}
Currently, hyperprolactinemia is considered as a condition to be excluded during the diagnosis of polycystic ovarian syndrome (PCOS), because it often demonstrates clinical signs similar to PCOS. However, some publications have reported "the prevalence of hyperprolactinemia in PCOS," which does not agree with the statement above statement. The publications presented in this review demonstrate conflicting approaches to considering the association of hyperprolactinemia and PCOS. On the one hand, the current consensus on the diagnosis of PCOS assumes the exclusion of patients with hyperprolactinemia, and on the other hand, some authors consider hyperprolactinemia as an acceptable condition and estimate its prevalence in PCOS. Based on the analysis of the literature, we have demonstrated a contradictory attitude towards the association between hyperprolactinemia and PCOS. To overcome the contradiction, we consider it appropriate to use the term "potential PCOS" before the final assessment of the contribution of hyperprolactinemia to the development of symptoms similar to PCOS. The final diagnosis of PCOS in the presence of hyperprolactinemia is possible only after its correction and reassessment of all symptoms.(International Journal of Biomedicine. 2021;11(4):480-483.)
\end{abstract}

Key Words: obstetricians-gynecologists $\bullet$ stress $\bullet$ professional burnout $\bullet$ biomarkers

For citation:Atalyan AV, Sharifulin EM, Lazareva LM, Nadelyaeva YaG, Suturina LV. PCOS and Hyperprolactinemia: Conflicting Conditions or Comorbidities? International Journal of Biomedicine. 2021;11(4):480-483. doi:10.21103/Article11(4)_BR1

Dolycystic ovarian syndrome (PCOS) is one of the 1 most common endocrine disorders in the female population. ${ }^{(1)}$ Currently, hyperprolactinemia is considered as a condition to be excluded during the diagnosis of PCOS, because it often demonstrates clinical signs similar to PCOS. However, some publications have reported "the prevalence of hyperprolactinemia in PCOS," which does not agree with the statement above statement.

The purpose of this brief review was to systematize the available conflicting data on the associations between hyperprolactinemia and PCOS.

The information search was conducted using Internet resources (PubMed, EMBASE) and literature sources for the years 2000-2021.

*Corresponding author: Alina V. Atalyan, PhD. Scientific Centre for Family Health and Human Reproduction Problems, Irkutsk, the Russian Federation.E-mail: atalyan@sbamsr.irk.ru
The epidemiology of PCOS is well studied, but the prevalence of the syndrome varies from $2.2 \%$ to $15 \%{ }^{(2-6)}$ depending on the diagnostic criteria used and the characteristics of the population sample. In women with an irregular menstrual cycle, the incidence of PCOS ranges from $16.5 \%$ to $46 \%$, and with anovulatory infertility - from $55 \%$ to $91 \%{ }^{(9,10)}$ Diagnosis of PCOS is based on the registration of clinical and laboratory manifestations of hyperandrogenism, assessment of menstrual and ovulatory function, as well as ovarian morphology using ultrasound. The Harmonized Criteria of the European Society for Human Reproduction and Embryology and the American Society for Reproductive Medicine (ASRM/ ESHRE), adopted in Rotterdam (2003), ${ }^{(1)}$ are currently used to diagnose PCOS. According to this consensus, the diagnosis of PCOS can be confirmed by the presence of at least two of the following three criteria: oligo- or anovulation, clinical or biochemical signs of hyperandrogenism, polycystic ovarian morphology on ultrasound. This approach to the diagnosis of PCOS is confirmed in the international recommendations for 
the assessment and treatment of PCOS, presented in 2018.(12) Clinical signs of hyperandrogenism include hirsutism, acne, and androgenetic alopecia. According to various sources, hirsutism occurs in the majority of women with $\operatorname{PCOS}^{(13-16)}$ and acne in $15 \%-25 \%$ of them; ${ }^{(17,18)}$ however, their diagnostic significance as a marker of hyperandrogenism is debatable. (19.20) Although androgenic alopecia is considered a sign of PCOS, the relationship between these states has not been definitively determined. ${ }^{(21)}$ Among the reproductive disorders associated with PCOS, the most important are infertility ${ }^{(22,23)}$ and miscarriage, as well as failures with IVF. ${ }^{(24,25)}$ At the same time, several scientists consider PCOS as a factor that does not affect the frequency of miscarriages. ${ }^{(26)}$ In patients with PCOS, the risk of developing preeclampsia and hypertension during pregnancy is up to four times higher, and the risk of premature birth is almost twice as high.(27) Along with reproductive disorders, PCOS is associated with insulin resistance, impaired glucose tolerance, and diabetes mellitus, as well as cardiovascular diseases, all of which determine the long-term consequences of this disease. ${ }^{(28)}$

The previous and current consensuses on the diagnosis of PCOS require the exclusion of other diseases with similar symptoms, including hyperprolactinemia.

Hyperprolactinemia is found in almost $30 \%$ of women with secondary amenorrhea and is a common cause of amenorrhea and infertility. There are many reasons for the development of this condition: physiological (pregnancy, lactation, exercise), taking medications that disrupt the production of dopamine (for example, antipsychotics, antidepressants, sequential contraceptives, antihypertensives, and others), primary hypothyroidism, and chronic renal failure. ${ }^{(7)}$ Like PCOS, hyperprolactinemia is often the cause of reproductive loss. (29) Hyperprolactinemia often demonstrates clinical signs similar to PCOS, and it is associated with excess androgen production by the adrenal glands in vivo and in vitro, ${ }^{(30,31)}$ suggesting a potential mechanism by which it may contribute to hyperandrogenism. Elevated prolactin levels are found in $6 \%$ of women with hirsutism. ${ }^{(32)}$ Therefore, when diagnosing PCOS, it is necessary to exclude hyperprolactinemia as a disease with similar symptoms.

However, some authors evaluated "the prevalence of hyperprolactinemia in PCOS," which contradicts the approved approaches to the diagnosis of PCOS. Thus, Filho et al. ${ }^{(33)}$ detected hyperprolactinemia in $16 \%$ of patients with PCOS. The authors showed that hyperprolactinemia is not a clinical manifestation of PCOS but is caused by other etiological factors, which logically requires further examination for other causes of hyperprolactinemia. Hayashida et al. ${ }^{(34)}$ found macroprolactinemia in $6 \%$ of cases in a group of 227 women with PCOS. In 2018, a study by Kyritsi et al. ${ }^{(35)}$ reported that the prevalence of idiopathic hyperprolactinemia in a group of 76 PCOS patients reached $26 \%$. A clinical case with twin sisters with signs of PCOS associated with idiopathic hyperprolactinemia was described by Goyal et al. ${ }^{\left({ }^{(6)}\right)}$ Several authors have suggested that PCOS causes hyperprolactinemia due to a relative hyperestrogenemia in anovulatory women. $(37,38)$ This hypothesis is supported by various experimental studies that have shown an increase in the secretion of prolactin under the influence of estrogens. ${ }^{(39)}$ Nevertheless, there are few studies on this topic, and none of them has convincingly demonstrated a clear pathogenetic link between PCOS and hyperprolactinemia.

Thus, the publications presented in this review demonstrate conflicting approaches to considering the association of hyperprolactinemia and PCOS. On the one hand, the current consensus on the diagnosis of PCOS assumes the exclusion of patients with hyperprolactinemia, and on the other hand, some authors consider hyperprolactinemia as an acceptable condition and estimate its prevalence in PCOS.

\section{Conclusion}

Hyperprolactinemia and PCOS are known as conditions with similar clinical manifestations, and current guidelines on PCOS diagnosis consider hyperprolactinemia as exclusion criteria. However, some authors indicate a proportion of patients with hyperprolactinemia and PCOS that does not correspond with the previously mentioned consensuses.

In our opinion, the data on the prevalence of hyperprolactinemia in women with signs of PCOS are of interest. However, itis bettertouse the term "potentialPCOS" in suchcases, and diagnose PCOS only when clinical signs of this syndrome occur after correction of hyperprolactinemia. According to this point of view, our brief review summarizes current research data assessing the frequency of hyperprolactinemia in "potential PCOS." Nowadays, the literature regarding the prevalence of hyperprolactinemia in women with symptoms of PCOS is still unclear, and more studies are needed, including those designed to estimate asymptomatic hyperprolactinemia with the evaluation of macroprolactin. ${ }^{(40,41)}$ Several studies have shown that approximately $40 \%$ of patients with hyperprolactinemia have macroprolactinemia. ${ }^{(42,43)}$ Because macroprolactinemia is a common cause of hyperprolactinemia, routine screening for macroprolactin could eliminate unnecessary diagnostic testing and treatment. ${ }^{(44,45)}$

Based on the analysis of the literature, we have demonstrated a contradictory attitude towards the association between hyperprolactinemia and PCOS. To overcome the contradiction, we consider it appropriate to use the term "potential PCOS" before the final assessment of the contribution of hyperprolactinemia to the development of symptoms similar to PCOS. The final diagnosis of PCOS in the presence of hyperprolactinemia is possible only after its correction and reassessment of all symptoms.

\section{Acknowledgments}

This article contains material that has been discussed at the VIII International Research and Practical Conference «FUNDAMENTAL AND APPLIED ASPECTS OF REPRODUCTION» (December 2021, Irkutsk, Russia). The author thanks all researchers who participated in the oral discussion.

\section{Competing Interests}

The authors declare that they have no competing interests. 


\section{References}

1. Belenkaia LV, Lazareva LM, Walker W, Lizneva DV, Suturina LV. Criteria, phenotypes and prevalence of polycystic ovary syndrome. Minerva Ginecol. 2019 Jun;71(3):211-223. doi: 10.23736/S0026-4784.19.04404-6.

2. Lizneva D, Suturina L, Walker W, Brakta S, GavrilovaJordan L, Azziz R. Criteria, prevalence, and phenotypes of polycystic ovary syndrome. Fertil Steril. 2016 Jul;106(1):615. doi: 10.1016/j.fertnstert.2016.05.003.

3. Lizneva D, Kirubakaran R, Mykhalchenko K, Suturina L, Chernukha G, Diamond MP, Azziz R. Phenotypes and body mass in women with polycystic ovary syndrome identified in referral versus unselected populations: systematic review and meta-analysis. Fertil Steril. 2016 Nov;106(6):1510-1520.e2. doi: 10.1016/j.fertnstert.2016.07.1121.

4. Chen X, Yang D, Mo Y, Li L, Chen Y, Huang Y. Prevalence of polycystic ovary syndrome in unselected women from southern China. Eur J Obstet Gynecol Reprod Biol. 2008 Jul;139(1):59-64. doi: 10.1016/j.ejogrb.2007.12.018.

5. Yildiz BO, Bozdag G, Yapici Z, Esinler I, Yarali H. Prevalence, phenotype and cardiometabolic risk of polycystic ovary syndrome under different diagnostic criteria. Hum Reprod. 2012 Oct;27(10):3067-73. doi: 10.1093/humrep/ des232.

6. Lauritsen MP, Bentzen JG, Pinborg A, Loft A, Forman JL, Thuesen LL, Cohen A, Hougaard DM, Nyboe Andersen A. The prevalence of polycystic ovary syndrome in a normal population according to the Rotterdam criteria versus revised criteria including anti-Mullerian hormone. Hum Reprod. 2014 Apr;29(4):791-801. doi: 10.1093/humrep/det469.

7. Azziz R, Carmina E, Dewailly D, Diamanti-Kandarakis E, Escobar-Morreale HF, Futterweit W, Janssen OE, Legro RS, Norman RJ, Taylor AE, Witchel SF; Task Force on the Phenotype of the Polycystic Ovary Syndrome of The Androgen Excess and PCOS Society. The Androgen Excess and PCOS Society criteria for the polycystic ovary syndrome: the complete task force report. Fertil Steril. 2009 Feb;91(2):45688. doi: 10.1016/j.fertnstert.2008.06.035.

8. Azziz R, Adashi EY. Stein and Leventhal: 80 years on. Am J Obstet Gynecol. 2016 Feb;214(2):247.e1-247.e11. doi: 10.1016/j.ajog.2015.12.013.

9. Chen X, Yang D, Mo Y, Li L, Chen Y, Huang Y. Prevalence of polycystic ovary syndrome in unselected women from southern China. Eur J Obstet Gynecol Reprod Biol. 2008 Jul;139(1):59-64. doi: 10.1016/j.ejogrb.2007.12.018.

10. Carmina E, Guastella E, Longo RA. Advances in the Diagnosis and Treatment of PCOS. Curr Pharm Des. 2016;22(36):5508-5514. doi: 10.2174/138161282266616071 9105808 .

11. Rotterdam ESHRE/ASRM-Sponsored PCOS consensus workshop group. Revised 2003 consensus on diagnostic criteria and long-term health risks related to polycystic ovary syndrome (PCOS). Hum Reprod. 2004 Jan;19(1):41-7. doi: 10.1093/humrep/deh098.

12. Teede HJ, Misso ML, Costello MF, Dokras A, Laven J, Moran L, Piltonen T, Norman RJ; International PCOS Network. Recommendations from the international evidence-based guideline for the assessment and management of polycystic ovary syndrome. Fertil Steril. 2018 Aug;110(3):364-379. doi: 10.1016/j.fertnstert.2018.05.004.

13. Cheewadhanaraks S, Peeyananjarassri K, Choksuchat C. Clinical diagnosis of hirsutism in Thai women. J Med Assoc
Thai. 2004 May;87(5):459-63.

14. Hahn S, Tan S, Elsenbruch S, Quadbeck B, Herrmann BL, Mann K, Janssen OE. Clinical and biochemical characterization of women with polycystic ovary syndrome in North RhineWestphalia. Horm Metab Res. 2005 Jul;37(7):438-44. doi: 10.1055/s-2005-870236.

15. Escobar-Morreale HF, Carmina E, Dewailly D, Gambineri A, Kelestimur F, Moghetti P, Pugeat M, Qiao J, Wijeyaratne CN, Witchel SF, Norman RJ. Epidemiology, diagnosis and management of hirsutism: a consensus statement by the Androgen Excess and Polycystic Ovary Syndrome Society. Hum Reprod Update. 2012 Mar-Apr;18(2):146-70. doi: 10.1093/humupd/dmr042. Epub 2011 Nov 6. Erratum in: Hum Reprod Update. 2013 Mar-Apr;19(2):207.

16. Legro RS, Arslanian SA, Ehrmann DA, Hoeger KM, Murad MH, Pasquali R, Welt CK; Endocrine Society. Diagnosis and treatment of polycystic ovary syndrome: an Endocrine Society clinical practice guideline. J Clin Endocrinol Metab. 2013 Dec;98(12):4565-92. doi: 10.1210/jc.2013-2350. Epub 2013 Oct 22. Erratum in: J Clin Endocrinol Metab. 2021 May 13;106(6):e2462.

17. Azziz R. PCOS: a diagnostic challenge. Reprod Biomed Online. 2004 Jun;8(6):644-8. doi: 10.1016/s14726483(10)61644-6.

18. Wijeyaratne $\mathrm{CN}$, Balen $\mathrm{AH}$, Barth $\mathrm{JH}$, Belchetz PE. Clinical manifestations and insulin resistance (IR) in polycystic ovary syndrome (PCOS) among South Asians and Caucasians: is there a difference? Clin Endocrinol (Oxf). 2002 Sep;57(3):343-50. doi: 10.1046/j.1365-2265.2002.01603.x.

19. Cunliffe WJ, Gould DJ. Prevalence of facial acne vulgaris in late adolescence and in adults. Br Med J. 1979 Apr 28;1(6171):1109-10. doi: 10.1136/bmj.1.6171.1109.

20. Galobardes B, Davey Smith G, Jefferys M, McCarron P; Glasgow Alumni Cohort. Has acne increased? Prevalence of acne history among university students between 1948 and 1968. The Glasgow Alumni Cohort Study. Br J Dermatol. 2005 Apr;152(4):824-5. doi: 10.1111/j.1365-2133.2005.06527.x.

21. Karrer-Voegeli S, Rey F, Reymond MJ, Meuwly JY, Gaillard RC, Gomez F. Androgen dependence of hirsutism, acne, and alopecia in women: retrospective analysis of 228 patients investigated for hyperandrogenism. Medicine (Baltimore). 2009 Jan;88(1):32-45. doi: 10.1097/ md.0b013e3181946a2c.

22. Suturina LV, Atalyan AV, Darzhaev ZY, Belenkaya LV, Baldano MN, Lazareva LM. Overweight and obesity prevalence in referral population of infertile women with polycystic ovary syndrome. Adv Obes Weight Manag Control. 2017;7(1):237-240. doi: 10.15406/aowmc.2017.07.00188

23. Kolesnikova LI, Kolesnikov SI, Darenskaya MA, Grebenkina LA, Nikitina OA, Lazareva LM, Suturina LV, Danusevich IN, Druzhinina EB, Semendyaev AA. Activity of LPO Processes in Women with Polycystic Ovarian Syndrome and Infertility. Bull Exp Biol Med. 2017 Jan;162(3):320-322. doi: 10.1007/s10517-017-3605-5.

24. Rehman R, Mehmood M, Ali R, Shaharyar S, Alam F. Influence of body mass index and polycystic ovarian syndrome on ICSI/IVF treatment outcomes: A study conducted in Pakistani women. Int J Reprod Biomed. 2018 Aug;16(8):529-534.

25. Bou Nemer L, Shi H, Carr BR, Word RA, Bukulmez O. Effect of Body Weight on Metabolic Hormones and Fatty Acid Metabolism in Follicular Fluid of Women Undergoing In Vitro Fertilization: A Pilot Study. Reprod Sci. 2019 Mar;26(3):404- 
411. doi: 10.1177/1933719118776787.

26. West S, Lashen H, Bloigu A, Franks S, Puukka K, Ruokonen A, Järvelin MR, Tapanainen JS, Morin-Papunen L. Irregular menstruation and hyperandrogenaemia in adolescence are associated with polycystic ovary syndrome and infertility in later life: Northern Finland Birth Cohort 1986 study. Hum Reprod. 2014 Oct 10;29(10):2339-51. doi: 10.1093/humrep/deu200.

27. Palomba S, Falbo A, Russo T, Tolino A, Orio F, Zullo F. Pregnancy in women with polycystic ovary syndrome: the effect of different phenotypes and features on obstetric and neonatal outcomes. Fertil Steril. 2010 Oct;94(5):1805-11. doi: 10.1016/j.fertnstert.2009.10.043.

28. Lazareva LM, Sharifulin EM, Belenkaya LV, Suturina LV. [Polycystic Ovary Syndrome in Women of Reproductive Age: Phenotypic Variety and Diagnostic Approaches. Review of Literature]. Doctor. Ru. 2020;19(6):50-56. DOI: 10.31550/1727-2378-2020-19-6-50-56.[Article in Russian] 29. Darzhaev ZYu, Atalyan AV, Rinchindorzhieva MP, Suturina LV. Prevalence of female infertility among urban and rural population in Buryat Republic. Fundamental and Clinical Medicine. 2017;2(4):14-21. doi:10.23946/2500-0764-2017-24-14-21.

30. Higuchi K, Nawata H, Maki T, Higashizima M, Kato K, Ibayashi H. Prolactin has a direct effect on adrenal androgen secretion. J Clin Endocrinol Metab. 1984 Oct;59(4):714-8. doi: 10.1210/jcem-59-4-714.

31. Schiebinger RJ, Chrousos GP, Cutler GB Jr, Loriaux DL. The effect of serum prolactin on plasma adrenal androgens and the production and metabolic clearance rate of dehydroepiandrosterone sulfate in normal and hyperprolactinemic subjects. J Clin Endocrinol Metab. 1986 Jan;62(1):202-9. doi: 10.1210/jcem-62-1-202. PMID: 2999177. 32. Hagag P, Hertzianu I, Ben-Shlomo A, Weiss M. Androgen suppression and clinical improvement with dopamine agonists in hyperandrogenic-hyperprolactinemic women. J Reprod Med. 2001 Jul;46(7):678-84.

33. Filho RB, Domingues L, Naves L, Ferraz E, Alves A, Casulari LA. Polycystic ovary syndrome and hyperprolactinemia are distinct entities. Gynecol Endocrinol. 2007 May;23(5):267-72. doi: 10.1080/09513590701297708.

34. Hayashida SA, Marcondes JA, Soares JM Jr, Rocha MP, Barcellos CR, Kobayashi NK, Baracat EC, Maciel GA. Evaluation of macroprolactinemia in 259 women under investigation for polycystic ovary syndrome. Clin Endocrinol (Oxf). 2014 Apr;80(4):616-8. doi: 10.1111/cen.12266.

35. Kyritsi EM, Dimitriadis GK, Angelousi A, Mehta H,
Shad A, Mytilinaiou M, Kaltsas G, Randeva HS. The value of prolactin in predicting prolactinoma in hyperprolactinaemic polycystic ovarian syndrome. Eur J Clin Invest. 2018 Jul;48(7):e12961. doi: 10.1111/eci.12961.

36. Goyal A, Ganie MA. Idiopathic Hyperprolactinemia Presenting as Polycystic Ovary Syndrome in Identical Twin Sisters: A Case Report and Literature Review. Cureus. 2018 Jul 19;10(7):e3004. doi: 10.7759/cureus.3004.

37. Azziz R, Carmina E, Chen Z, Dunaif A, Laven JS, Legro RS, Lizneva D, Natterson-Horowtiz B, Teede HJ, Yildiz BO. Polycystic ovary syndrome. Nat Rev Dis Primers. 2016 Aug 11;2:16057. doi: 10.1038/nrdp.2016.57.

38. Robin G, Catteau-Jonard S, Young J, Dewailly D. Lien physiopathologique entre syndrome des ovaires polymicrokystiques et hyperprolactinémie: mythe ou réalité? [Physiopathological link between polycystic ovary syndrome and hyperprolactinemia: myth or reality?]. Gynecol Obstet Fertil. 2011 Mar;39(3):141-5. doi: 10.1016/j. gyobfe.2010.11.002. [Article in French].

39. Touraine P, Goffin V. Physiologie de la prolactine. EM Consulte. 2015;11(1):1-13. doi : 10.1016/S02461064(15)65068-X. [Article in French].

40. Chahal J, Schlechte J. Hyperprolactinemia. Pituitary. 2008;11(2):141-6. doi: 10.1007/s11102-008-0107-5. PMID: 18404389.

41. Glezer A, Soares CR, Vieira JG, Giannella-Neto D, Ribela MT, Goffin V, Bronstein MD. Human macroprolactin displays low biological activity via its homologous receptor in a new sensitive bioassay. J Clin Endocrinol Metab. 2006 Mar;91(3):1048-55. doi: 10.1210/jc.2005-1831.

42. Donadio F, Barbieri A, Angioni R, Mantovani G, Beck-Peccoz P, Spada A, Lania AG. Patients with macroprolactinaemia: clinical and radiological features. Eur J Clin Invest. 2007 Jul;37(7):552-7. doi: 10.1111/j.13652362.2007.01823.x.

43. McKenna TJ. Should macroprolactin be measured in all hyperprolactinaemic sera? Clin Endocrinol (Oxf). 2009 Oct;71(4):466-9. doi: 10.1111/j.1365-2265.2009.03577.x.

44. Gibney J, Smith TP, McKenna TJ. The impact on clinical practice of routine screening for macroprolactin. J Clin Endocrinol Metab. 2005 Jul;90(7):3927-32. doi: 10.1210/ jc.2004-2234.

45. Melmed S, Casanueva FF, Hoffman AR, Kleinberg DL, Montori VM, Schlechte JA, Wass JA; Endocrine Society. Diagnosis and treatment of hyperprolactinemia: an Endocrine Society clinical practice guideline. J Clin Endocrinol Metab. 2011 Feb;96(2):273-88. doi: 10.1210/jc.2010-1692. 